Published in final edited form as:

Cardiovasc Intervent Radiol. 2004 ; 27(5): 427-434.

\title{
Radiofrequency Ablation of Cancer
}

\author{
Marc Friedman $^{1}$, Igor Mikityansky ${ }^{1,2}$, Anthony Kam ${ }^{1}$, Steven K. Libutti ${ }^{3}$, McClellan M. \\ Walther $^{4}$, Ziv Neeman ${ }^{1}$, Julia K. Locklin ${ }^{1}$, and Bradford J. Wood ${ }^{1,3}$ \\ 1 Diagnostic Radiology Department, Special Procedures Division, National Institutes of Health, Clinical \\ Center, Bethesda, MD 20892
}

2Diagnostic Radiology Department, University of Rochester School of Medicine and Dentistry, Rochester, NY 14642

3Surgery Branch, National Cancer Institute, National Institutes of Health, Bethesda, MD 20892

4Urologic Oncology Branch, National Cancer Institute, National Institutes of Health, Bethesda 20892

\begin{abstract}
Radiofrequency ablation (RFA) has been used for over 18 years for treatment of nerve-related chronic pain and cardiac arrhythmias. In the last 10 years, technical developments have increased ablation volumes in a controllable, versatile, and relatively inexpensive manner. The host of clinical applications for RFA have similarly expanded. Current RFA equipment, techniques, applications, results, complications, and research avenues for local tumor ablation are summarized.
\end{abstract}

\section{Keywords}

Radiofrequency ablation; Tumor/neoplasm; Colon carcinoma; Hepatocellular carcinoma; Hyperthermia

Radiofrequency ablation (RFA) is a modified electrocautery technique [1] that has emerged as the frontrunner among the many choices for local, minimally invasive tissue ablation. It is effective, versatile, and relatively inexpensive. RFA has been used for years in the treatment of cardiac dysrhythmias from aberrant conduction pathways [2], osteoid osteoma [3], prostate hypertrophy [4], and chronic pain [5]. Recent clinical applications include tumor ablation in the liver [6-8], kidney [9,10], adrenal gland [11,12], bone [13], lung [14], and breast [15] as well as soft tissue debulking and pain palliation [16].

Radiofrequency electric fields drive ionic currents in tissue and cause resistive heating. At 50$52^{\circ} \mathrm{C}$, cells undergo coagulation necrosis in 4-6 minutes; for temperatures greater than $60^{\circ} \mathrm{C}$, coagulation necrosis is instantaneous. With single needle nonperfused electrodes, coagulation diameters are limited to about $1.6 \mathrm{~cm}$. Recent advances in RFA technique have resulted in larger volumes of tissue ablation ( $7 \mathrm{~cm}$ diameter in a $30 \mathrm{~min}$ session) with relatively low complication rates and minimal collateral damage. There are a variety of methods for increasing coagulation volume with RFA. The most successful of these are slow or pulsed heating, multiprobe array electrodes [17], internal electrode cooling [18], and saline infusion [19,20].

\section{Equipment}

There are four RFA systems available in the United States: Boston Scientific (Watertown, MA; formerly Radio Therapeutics Corporation, Mountain View, CA), Radionics Valley Lab 
(Burlington, MA), RITA Medical Systems (Mountain View, CA), and Berchtold (Tuttlingen, Germany). All are Food and Drug Administration 510K cleared for soft tissue ablation. The Boston Scientific and RITA Medical systems also have 510K clearance for unresectable liver tumors, and RITA is cleared for bone metastases as well. The four systems differ in needle electrodes, generators, and the algorithms used to maximize coagulation volumes.

The Boston Scientific electrode is a 14-gauge cannula through which an array of 10 to 12 hooked tines are coaxially deployed after the cannula is placed into the tumor. The deployed tines assume the shape of an umbrella. There are several electrodes with array diameters ranging from 2 to $4 \mathrm{~cm}$. A coaxial needle system has the advantage that the needle remains stationary when the target moves. This may be relevant with a hepatic dome tumor approached subcostally. A coaxial system also may create a more spherical ablation. The Boston Scientific RF 3000 generator is rated to $200 \mathrm{~W}$ at $460 \mathrm{kHz}$ and operates with impedance control. Power is increased incrementally until impedance increases to a peak level, where it is maintained for 15 minutes or until impedance rises abruptly ("roll off"). When roll off occurs, it is restarted at $70 \%$ of peak power for 15 more minutes or until roll off occurs again.

In the Radionics system, the needle electrode is 17.5 gauge and insulated up to several $\mathrm{cm}$ from the tip. The exposed lengths range from 1 to $3 \mathrm{~cm}$. The shaft of the electrode contains two channels through which chilled water flows. By minimizing charring and desiccation around the electrode tip, internal cooling yields a larger coagulation volume [18]. Radionics' cooled single needle electrode can achieve a coagulation diameter of 3.3-4.1 cm [21]. To increase the coagulation volume further (> 3.5, up to approximately $6.5 \mathrm{~cm}$ diameter), Radionics offers three cooled needles in a triangular cluster on a common handle. The Radionics generator has a maximal output of $200 \mathrm{~W}$ at $480 \mathrm{kHz}$ and is an impedance-controlled system. The power is ramped to a maximal value over about one minute. The maximum power is maintained until the impedance increases by $20 \Omega$ or 12 minutes. If impedance rises, the power is switched to a nominal $10 \mathrm{~W}$ for 15 seconds, and then back again to the maximal power. If the power level cannot be maintained for $10 \mathrm{~s}$, the subsequent power levels are reduced. These cycles are continued for an ablation time of 12 minutes. The tip of the electrode contains a thermocouple used to monitor tissue during cooling after treatment. A tissue temperature of more than $60^{\circ}$ $\mathrm{C}$ at 3 minutes of cooling after the 12-minute treatment usually indicates an adequate ablation. Maximum temperature post-RFA should exceed $70^{\circ} \mathrm{C}$.

In the RITA Medical system there are three models of the multiprobe array electrode: Starburst $\mathrm{XL}$, Starburst XLi, and Starburst Flex. The Starburst XL consists of a 14-gauge cannula housing an array of 9 tines. When fully extended, the tines assume the configuration of a Christmas tree with a maximal diameter of $5 \mathrm{~cm}$. The tines can also be partially deployed to ablate a smaller volume. There are 5 integrated thermocouples in the 9 tines, all of which are active. The Starburst XLi also consists of a 14-gauge cannula with a live trocar tip housing an array of 9 tines which can be deployed to a maximal diameter of $7 \mathrm{~cm}$. However, 4 of the tines are dedicated thermocouples; 5 are hollow active electrodes through which normal saline is infused. By preventing charring in the target area, saline infusion increases tissue electrical and thermal conductivity. The Starburst Flex electrode is similar to the Starburst XL except that the cannula is 13 gauge and flexible, and it requires an 11-gauge introducer. This flexibility may be helpful to fit the probe into a CT gantry. An MR-compatible version of this needle recently became available.

The RITA Medical 1500x generator has a maximal power of $250 \mathrm{~W}$ at $460 \mathrm{kHz}$; it is a temperature-controlled system. With the tines retracted, the power is increased to a maximal value of over 0.5-2 minutes. The peak power is maintained until the temperatures at the electrode tips exceed a target value. The tines are deployed in increments. After the tines are deployed to a target diameter, the power is regulated to maintain the target temperature. 
Temperatures of deployed electrodes of more than $50^{\circ} \mathrm{C}$ at 1 minute after ablation usually indicate an adequate ablation.

In the Berchtold system, the electrode is an 18-gauge to 14-gauge hollow needle with laserbored microholes near the tip. The various electrodes have active tips ranging from 1 to $2 \mathrm{~cm}$. There are two needle electrodes that are MRI-compatible and FDA-cleared. Isotonic saline is infused through the needle electrode at a constant rate of about 20-40 drops $/ \mathrm{min}$. A bolus of saline is given when the patient loop impedance exceeds $900 \pm 50 \Omega$. The Berchtold generator is rated to $60 \mathrm{~W}$ at $375 \mathrm{kHz}$, it is an impedance-controlled system with an option for additional thermistors. When the temperature control mode is selected, there is an additional power regulation to maintain a constant temperature at the temperature sensor. With this system, a 5$\mathrm{cm}$ ablation can supposedly be obtained in about 15 minutes. The lower wattage may be more susceptible to heat sink convection, and the high saline flow may result in a wider range of ablation sizes, however.

\section{Practical Clinical Technique}

Pre-procedural evaluation may include triphasic CT, MRI, ultrasound (US), PT/PTT, CBC, Chemistry 12, LFT's, CEA, AFP, hepatitis panel, EKG, and a type and screen. RFA can be performed with percutaneous, laparoscopic, or open-surgical approaches. The choice depends on the condition of the patient, tumor size, number, location, growth pattern, and operator and local practice patterns.

The percutaneous approach requires that tumors not lie adjacent to the bowel or other organs which can be injured by thermal conduction. Procedural pain may be somewhat predictable based upon risk factors of capsular or diaphragmatic burn, prior surgery, or long procedure times. General anesthesia, conscious sedation, or deep sedation may all be appropriate.

For laparoscopic or surgical RFA, the patient must not be at high risk for general anesthesia. Surgical approaches allow a more accurate evaluation of disease in and outside of the organ and less risk to adjacent structures like bowel. Intraoperative ultrasound remains the most sensitive imaging test for hepatic lesions, and may pick up as many as $38 \%$ more lesions than preoperative imaging [22]. Mobilizing organs may protect them from thermal injury. The laparoscopic approach is easier near the surface of the organ. Carbon dioxide or saline may be injected percutaneously in CT for the same effect however (manuscript under review). With the surgical approach, the vessels supplying the organ of the tumor can be clamped, eliminating cooling from perfusion. In addition, the open approach allows concurrent combination therapies like resection and placement of pumps for regional chemotherapy.

One to four grounding pads are placed on the thighs or back in order to complete an electrical circuit. A more uniform thermal lesion is created when the rectangular pads are placed with the long side transverse with respect to the needle, with less risk of pad burns [69].

In the percutaneous approach using conscious sedation, the patient should not be so deeply sedated that they cannot follow breathing commands. Local anesthesia is given down to the organ capsule. If a guiding needle is used, the needle electrode is placed by a tandem technique. If pain is intolerable early in treatment, the generator can be turned down or off and the pain should abate in under 30 seconds. Treatment may begin again after more sedation is administered. Sedation should be bolused just before the current is turned on.

RFA for palliation or debulking may not require treating a margin of normal tissue. Usually, the goal of RFA is complete ablation of the tumor with a $1-\mathrm{cm}$, tumor-free or surgical margin. A surgical margin is necessary because of the uncertainty in delineating the exact margin of a tumor and the possibility of microscopic tumor surrounding the visible tumor. The 1-cm margin 
may be excessive in the kidney, when there may be a secondary goal to preserve renal parenchyma.

When the ablation volume does not achieve an adequate margin, overlapping ablations have to be performed. This may require more treatment spheres than one would imagine. For example, ablating a $3-\mathrm{cm}$-diameter tumor with $1-\mathrm{cm}$ margins is equivalent to treating a $5-\mathrm{cm}$ sphere. If a needle electrode can create $3-\mathrm{cm}$ diameter ablations, a minimum of 14 perfectly placed ablations is needed to cover the $5-\mathrm{cm}$ sphere using a mathematical model [23]. There is no consensus on maximum tumor size in the liver. Because of the high number of ablations needed to treat large tumors, the size of tumor that is practical for RFA is limited to near $5 \mathrm{~cm}$. Larger tumors may be attempted, but with added risk and less success rates. Systemic or regional therapies may also need to be added to RFA.

A tumor that lies adjacent to blood vessels more than $3 \mathrm{~mm}$ in diameter (or vessels seen on CT or MR) is more difficult to ablate because of convective cooling by bulk blood flow [70]. To completely ablate such a tumor, the blood vessel may have to be occluded by surgical clamping, occlusion balloon, or embolization. There is no consensus, however, hepatic vein occlusion balloons may be the easiest method. We typically leave the occlusion balloon up for 3 minutes, then down for 30 seconds to theoretically decrease the risk of hepatic vein thrombosis. A more common approach may be to combine RFA with bland or chemoembolization, although this may add risk. Also, the timing and sequence are yet to be optimized. If occlusion is not feasible, then targeting the vessel with the RF probe near but not in the vessel may afford better outcomes, anecdotally.

US and/or CT (followed by MR) are most commonly used for guidance. We use CT alternating with US to provide maximum visualization during different stages of the procedure. During ablation, hyperechogenicity from microbubbles expands from the needle electrode on US. Because of its variability, the extent of hyperechogenity does not exactly correlate with the extent of coagulation necrosis [24], but it is helpful for continuous monitoring. We often give miniboluses of $50 \mathrm{cc}$ iodinated contrast to visualize a tumor or thermal lesion in CT during the procedure and to choose the next target area. Post-procedure contrast-enhanced CT or MR is used to determine the extent of coagulation. Lack of enhancement has been shown to correlate with coagulation necrosis $[25,26]$. A thin rim of enhancement corresponding to a hyperemic inflammatory reaction or hemorrhagic granulation tissue is normal. This enhancement usually resolves in about one month [25].

Follow-up imaging depends on tumor location, growth rate, histology, organ, and risk of incomplete treatment. Although there is no consensus, one recipe calls for follow-up imaging at 2- to 6 weeks, then every 3 months for more than 1 year. Residual enhancement, increase in size of ablation region, or increase in irregularity or nodularity of ablation region suggests recurrent tumor [25]. Retreatment should be early before tumor grows into a difficult geometry.

The use of prophylactic antibiotics is controversial. Hepatic abscess is a fairly rare complication of RFA in the liver. One patient died of Staphylococcus aureus peritonitis after RFA of hepatocellular carcinoma [27]. The infection was attributed to a break in sterile technique. We use pre-procedural prophylactic antibiotics routinely and a prophylactic course in certain highrisk situations. For RFA of liver tumors, we administer an antibiotic course to patients with severe cirrhosis, immunosuppression, large tumors, central tumors, ascites, prior hepatic artery therapy (pump or chemoembolization or embolization) or biliary pathology (dilated ducts, biliary-enteric anastomoses, or prior sphincterotomy). For RFA of renal tumors, the antibiotics are continued for 1 week after the ablation if the thermal lesion touches the collecting system or there is a history of reflux or recurrent urinary infections. 


\section{Clinical Applications}

\section{Hepatic Tumors}

Hepatocellular carcinoma (HCC) is the most common solid cancer in the world, with an increasing incidence in western countries [28]. It is rapidly fatal in most patients. The median life expectancy for untreated HCC ranges from less than 1 month to 18 months, depending on the degree of cirrhosis [29]. Surgical resection and transplantation are the only treatments that are considered curative. However, only $10-20 \%$ of patients with HCC have resectable disease [30]. Contraindications to resection include extrahepatic disease, multifocal disease, tumor adjacent to major vascular or biliary structures, and insufficient hepatic reserve. Liver transplantation is limited by the availability of donor organs. Patients with Child's C cirrhosis are often not candidates for RFA since the life expectancy is usually limited by the severe cirrhosis, and not by concomitant small HCC.

The liver is the second most common site of metastasis from solid cancers. It is the most common site of metastasis for colorectal carcinoma, and it is not uncommon to find the liver as the only site of metastasis. Without treatment, patients with liver metastases from colorectal carcinoma and other cancers have a median survival time of less than 1 year [31,32]. Surgical resection is the only curative treatment. Resection of liver-only metastases has yielded 5-year survival rates of $20-40 \%$ [33]. However, less than $25 \%$ of patients with liver-only metastases are candidates for a curative resection [33,34]. Contraindications to resection include bilobar disease, more than four metastases, or adjacent major vascular or biliary structures. Recurrence after curative resection can be as high as 70\% [34].

Because the majority of patients with primary and metastatic liver cancer are not candidates for surgical resection, local treatments are attractive. Since the pioneering work of McGahan et al. [35] and Rossi et al. [36] in 1990, there has been extensive work on RFA of liver tumors. Major clinical results of liver RFA are reviewed.

Studies of over 3,000 patients treated with RFA have shown the efficacy of percutaneous RFA for small $(<3.0 \mathrm{~cm}) \mathrm{HCC}$. Techniques for hepatic RFA vary by probe type, number of insertions, and number of treatment sessions. Recurrence rates are determined predominantly by lesion size, with lesions $<3.0 \mathrm{~cm}$, yielding a successful treatment in the vast majority. Complete local response averages $70-75 \%$ with tumors between 3.0 and $5.0 \mathrm{~cm}$, and drops to $25 \%$ in large tumors over $5 \mathrm{~cm}$ in diameter [37-41]. Advances in adjuvant therapies, such as hypertonic saline and liposomal chemotherapy, should enable better treatment of these larger tumors. With successful ablation, 5-year survival rates of 40-50\% have been reported for HCC. While local recurrences may be successfully treated, new intrahepatic or extrahepatic disease arises in $25-45 \%$ of patients [37-41].

This pattern of excellent local control for small HCC with significant long-term non-local recurrence is also true in RFA of hepatic metastases. In studies totaling over 1000 patients, hepatic metastases were treated with percutaneous, laparoscopic and open-surgical approaches and the full gamut of RF devices. Similar to HCC RFA, lesion size $>3.0 \mathrm{~cm}$ was associated with recurrence. In addition, the type of tumor was related to the recurrence rate; adenocarcinoma and sarcoma metastases recurred more often than neuroendocrine metastases or HCC. Both local and non-local recurrences were more frequent with metastases than with HCC. RFA for metastases was associated with improved survival, and should increase the number of patients eligible for surgical resection [42-46].

The above clinical results, dependent on the available RF technology, should be interpreted with reservations. As the technology evolves, the size of tumor than can be completely ablated in one or two needle insertions will also change. Also, RFA technique is operator-dependent. 
There is no consensus on the length of follow-up or outcomes criteria. There are no randomized prospective controlled studies comparing liver RFA to standard surgical resection in any populations. Most studies are retrospective, short-term reports. The significant rate of nonlocal recurrence reflects the natural course of HCC or metastatic disease. This argues for a multimodality approach to liver cancer. In general, patients are considered for RFA of their liver tumors if they are not surgical candidates, have 4 or fewer lesions, and have lesions smaller than $5 \mathrm{~cm}$ [43]. Relative contraindications to percutaneous RFA include presence of unstable extrahepatic disease, lesions adjacent to other organs, and uncontrolled coagulopathy.

\section{Extrahepatic Tumors}

Kidney-Another clinical application for RFA is the treatment of kidney tumors. The conventional treatment for renal cell carcinoma in patients with a functional contralateral kidney has been radical nephrectomy. In recent years, there has been a shift towards partial nephrectomy as a nephron-sparing procedure.

Increasing numbers of small renal tumors are being discovered incidentally, presenting difficult management issues. Both CT imaging and core biopsy yield a considerable non-diagnostic rate. In one study, the non-diagnostic rate was $20 \%$ by $\mathrm{CT}$ and $21 \%$ by biopsy [47]. The standard radical or partial nephrectomy may be excessively invasive for these undiagnosed lesions. RFA may offer a minimally invasive treatment alternative for small renal masses. RFA is especially appealing for patients with a genetic predisposition to multiple bilateral metachronous renal cancers, such as von-Hippel Lindau (VHL) or hereditary papillary renal cancer (HPRC).

Reports demonstrate that renal RFA is most effective in tumors less than $3 \mathrm{~cm}$ in diameter [48-50]. With increasing size, there is an increased risk of local recurrence. A majority of the renal tumors treated in these three series were exophytic or cortical. Ablation of medullary tumors in close proximity to the hilum are at higher risk of incomplete treatment due to the heat-sink effect of large renal vessels. As the number of patients treated is relatively small and follow-up short, more studies need to be undertaken to verify the efficacy of renal RFA compared to standard care. However, early short-term results suggest a 70-90\% success rate for small kidney tumors. With secondary ablations, even higher numbers may be achieved, however, success rates remain highest for small exophytic tumors $[9,10,49]$.

In our experience of well over one hundred kidney tumor ablations with RFA, we have had only two major complications (one urinoma in a patient with preexisting hydronephrosis and 6 tumors ablated, and one ureter stricture from successful ablation of a tumor touching ureter). Hematuria is usually self-limited in the hours following RFA. Paresthesias and nerve damage can be caused by tumors touching the psoas. Tumors touching the bowel should be done laparoscopically, or with maneuvers to move the bowel (carbon dioxide injection), in experienced centers.

Renal RFA is also being explored for hematuria control [51]. In these cases, the tumorcollecting system border is targeted for ablation. A surgical margin is not necessary, depending on whether nephron-sparing is a priority. In our limited experience in 5 cases (manuscript under review) RFA has been successful in cases of failed embolization as well as in place of catheterbased techniques.

Bone-RFA therapy can also be effectively applied to bony lesions, both benign and malignant. For over 10 years, it has been used to treat osteoid osteoma, a benign, slow-growing painful lesion [52]. While the pain is relieved by nonsteroidal antiinflammatory agents, symptoms can persist for years and surgery is the definitive treatment. As osteoid osteomas can grow in weight-bearing bones and vertebral bodies, there can be significant morbidity and extensive rehabilitation following surgical resection. An additional problem is localizing the 
lesion during surgery to remove the tumor in its entirety, while sparing normal bone. With RFA, the probe is placed through a bone-penetration cannula into the lesion and activated for 4-6 minutes at $90^{\circ} \mathrm{F}$ [53]. Success rates for a single ablation osteoid osteoma range from 9194\% with long-term follow-up, and most recurrences can be completely ablated in a second procedure [54]. Treatment of osteomas by RFA is highly effective, safe and allows early return to function while minimizing morbidity.

$\mathrm{RF}$ is also being investigated for ablation of bony metastases [55]. The conventional treatments for these lesions (chemotherapy, radiation and drugs) may be unable to completely abate pain. RFA may offer an alternative for the palliation of bony metastases. In a large, multicenter study, 43 patients with single, painful bone metastases, which were resistant to chemotherapy or radiation therapy, were treated with RFA under general anesthesia [56]. They reported a marked decrease in pain scores and analgesic use. This technique was modified for metastases in pathologic fracture by combination with cementoplasty, with good results at another clinical center [57].

Pain-RFA may provide palliation for painful bone or soft tissue metastases. A tumor margin is not required for relief of pain symptoms. Pain relief may result from decreased tumor compression on adjacent structures, ablation of pain fibers, a decrease in interstitial pressure, or decrease in cytotoxic substances from the tumor itself. RFA may provide rapid pain relief (in hours to days) for patients with cancer pain resistant to conventional forms of palliation in comparison to the radiation therapy, which palliates over the course of 7-21 days [58].

While RFA has been used to treat a number of pain syndromes including low back pain, trigeminal neuralgia, and other neurolysis, research into the palliative use of RFA is in its infancy. To address this shortcoming, there are currently ongoing trials at the National Institutes of Health for painful soft-tissue neoplasms, and through ACRIN (American College of Radiology Imaging Network) for painful bone tumors resistant to traditional techniques. In a preliminary report on RFA for soft tissue cancer pain palliation, pain inventory scores were lower for 14 patients treated with RFA for refractory pain from 1 week to 3 months after RFA (manuscript under review).

Lung-Primary or metastatic lung cancer may be recalcitrant to conventional therapies. While experience with RFA in the lung is nascent, early results are promising. To date, hundreds of patients have been treated with lung RFA [59,60]. However, clinical data are limited and require larger patient populations to determine the efficacy of lung cancer ablation.

RFA of these lesions in patients who are inoperable or refuse surgery presents different problems than ablation in other organs. The usually mild complication of pneumothorax is common, with a reported rate of 15-20\% [59,60]. In addition, Rose et al. [61] documented microemboli in the carotid artery during lung RFA. The clinical significance of these microemboli warrants further controlled investigation, as lack of the lung filtering mechanism places the cerebral vasculature in theoretical jeopardy for neurologic deficit. However, there is growing data that lung RFA is as safe and effective as in other organs, especially when performed remote from the main pulmonary veins.

Breast-Similar to the lung, RFA of breast cancer is in the early stages of development. The largest study to date is in 26 patients with T1 or T2 breast tumors [15]. Coagulation necrosis was confirmed by histology in $96 \%$ of the patients following surgical lumpectomy. However, there was one case of tumor seeding, with viable cancer cells along the needle track. This was reported using the RF system which cannot cauterize the track during probe removal. With more research and refinement of procedural methods, RFA of breast cancer may be an 
alternative breast-conserving treatment in the future. Several clinical trials for breast RFA are underway.

Adrenal-RFA may prove to be useful in patients with primary or metastatic adrenal tumors, as an alternative to surgery. Surgical resection may improve survival, so extrapolation suggests that aggressive local ablation may also do so. Eight patients with 15 primary adrenocortical carcinomas were treated with RFA, with high success rates for short-term destruction of tumors less than $5 \mathrm{~cm}$ in diameter [11]. Adrenal metastases, pheochromocytoma, and hormonally active tumors have also been treated with RFA [12]. Whether this preliminary data will translate into survival benefit is unknown. Hypertensive crisis has been reported during adrenal and lower-liver RFA.

Other-Other potential applications of RFA include the prostate, head and neck, thyroid, parathyroid, pancreas, lymph nodes, brain and bladder. The role of RFA in these organs requires further study.

\section{Complications}

One of the most frequently encountered problems in RFA is pain, which may be related to the size and location of the ablated lesion. Large, subcapsular, porta hepatis, or peri-diaphragmatic lesions tend to be more painful, and one may consider general anesthesia. Post-procedural pain is routinely diminished in 12 hours and often gone in 24 hours. Patient-controlled analgesia systems may be helpful in the first 12 hours post-RFA. Ketorolac provides effective pain control after RFA although it should be restricted to 1-2 doses to limit renal toxicity. Antiemetics and analgesics are also helpful, as needed.

Low-grade fever may occur in the first few days after RFA, especially with large ablations. Post-RFA syndrome is generally much less symptomatic than the typical post-embolization syndrome or post-tumor lysis syndrome. Fever at or above $101^{\circ} \mathrm{F}$ needs to be investigated, cultured, and treated. The ablation focus is a protein-rich media for bacteria. Liquified abscesses should be drained. Persistent gas can be seen in thermal lesions and in abscesses.

Both tumor seeding and back bleeding can be prevented by cauterization of the needle track. This is done by turning down the output and dragging the needle slowly out while the temperature or impedance are monitored. Injecting Gel-foam pledgets through a coaxial sheath to decrease back-bleeding has also been described. The needle track seeding rate is minimal $[39,44,45]$. Direct puncture of surface lesions carries a higher risk for bleeding, and likely for seeding as well [46].

Pneumothorax may be seen with a transthoracic approach to hepatic or lung lesions. Pleural effusion may be seen in cases where treatment is adjacent to pleura, as in liver dome lesions. Small and asymptomatic pneumothoraces or pleural effusions tend to resolve spontaneously and do not require chest tube placement or drainage. Sterile pleural effusions may take weeks to resolve. Shoulder pain is common and may also persist and is related to diaphragmatic burn.

Skin burns can occur if the grounding pads are improperly placed. Ensuring there are no creases in the grounding pads and increasing the total grounding pad area can prevent burns. Pads may feel warm without burning the patient. Frequent checks limit burn risk.

Livraghi et al. [46] have reported the complications of RFA of hepatic tumors from the collaborative Italian group using cooled-needle electrodes. This retrospective study involved 2,320 patients with 3,554 hepatic lesions. With these large numbers, this is a representative study. There were 6 deaths (0.3\%): 2 from multi-organ failure after intestinal perforation, 1 from septic shock after peritonitis, 1 from massive hemorrhage after tumor rupture, 1 from 
liver failure after development of a stricture in the right bile duct, and 1 from sudden death of an unknown cause. There were major complications in 50 patients $(2.2 \%)$. The most common were peritoneal bleeding requiring treatment, needle-track seeding, hepatic abscess requiring treatment, perforation of a gastrointestinal wall requiring surgery, hemothorax requiring drainage, and hepatic decompensation. There were minor complications in 110 patients $(4.7 \%)$, the most common being pain developing 3 days after the ablation, self-limited intraperitoneal bleeding, transient liver decompensation, asymptomatic arterioportal shunt, and biliary portal shunt with hemobilia. Careful patient selection, planning, and technique are needed to minimize complications.

Transient hematuria may be infrequently seen in renal ablations that involve the collecting system and usually resolves over hours. Renal RFA adds the risks of urinoma, ureteral stricture, and renal insufficiency. Pre- and post-procedural hydration should be as aggressive as the patient's medical condition allows. Aggressive hydration may limit renal toxicity from tumor lysis and may decrease the symptoms of the post-embolization syndrome.

\section{Areas of Ongoing Research}

RFA is a minimally invasive, safe and effective modality with great potential for local tumor destruction. Its role in ablation of liver cancer is well documented and serves as a practical alternative in inoperable patients. Also, RFA can play an important role as an adjunct to surgery and may convert a patient from inoperable to operable. It can even be used to temporize a patient's cancer while waiting for a liver transplant; each ablation can buy time until the patient comes off the transplant list [63].

Combination of RFA with other treatments is an area of active research. Larger liver tumors may be more easily treated by RFA plus vascular occlusion via Pringle maneuver or balloon occlusion [64,65]. Liposomal doxorubicin combined with RFA significantly increases ablation size [66]. Other options for improving upon ablation size include addition of hypertonic saline [71], acetic acid injection, percutaneous ethanol injection (PEI), chemoemoblization or cryoablation. Adding chemoembolization with doxorubicin markedly increases the volume of ablation [72] although the optimal timing and sequence have not been well defined.

Imaging of ablation, both during and after the procedure, is an area that requires further research. The enhancement of the post-treatment inflammatory granulation rind may be difficult, if not impossible, to differentiate from recurrent or untreated tumor with morphologic imaging. In many cases tumor is more nodular or irregular [26]. MRI may have some advantage over CT for follow-up of liver RFA. PET can help discriminate between irregular fibrosis and neoplastic tissue with much higher sensitivity than CT or MRI, if FDG-avid [67]. Microbubble contrast agents with US may also assist in determining local recurrence [68].

The natural history of treated tumor in the liver and kidney is slow shrinkage over the course of months to years, although scars may be permanent. In the liver and kidney, nodular or irregular peripheral contrast enhancement suggests local recurrence. However, identification of incomplete treatment criteria need to be further elucidated, and there is an organ-specific learning curve to post-RFA image interpretation.

Patient selection is important for successful treatment with RFA. It should be based upon location, tumor size, proximity of large vessels, bleeding risk, respiratory motion, probe pathway, and physician's experience. The technique is operator-dependent with a steep learning curve; consultation with an experienced physician is a valuable way to gain needed experience.

While there is ample data and follow-up for RFA in the liver, only preliminary results are available for RFA in other organs, and its long-term efficacy has yet to be proven by 
randomized, prospective trials. It may allow an increase in the rate of curative liver resections, decrease hospital stays, help avoid or postpone open surgery and general anesthesia, and provide symptomatic relief where other modalities have failed. It is fast, predictable, safe, relatively cheap, and versatile. It can be performed percutaneously, laparoscopically, or during open surgery. Although RFA is a nascent technique, initial results are promising. Multicenter trials, long-term follow-up studies, further refinements in technique, and RFA combination with adjuvant therapies are all underway.

\section{References}

1. Rai R, Barakat O, Rose J, Manas D. Role of radiofrequency ablation in multimodality management of unresectable liver tumours. J Gastrointest Surg 2003;7:263-264.

2. Calkins H, Epstein A, Packer D. Catheter ablation of ventricular tachycardia in patients with structural heart disease using cooled radio-frequency energy: results of a prospective multicenter study. Cooled RF Multi-Center Investigators Group. J Am Coll Cardiol 2000;35:1905-1914. [PubMed: 10841242]

3. Vanderschueren GM, Taminiau AH, Obermann WR. Osteoid osteoma: clinical results with thermocoagulation. Radiology 2002;224:82-86. [PubMed: 12091665]

4. Hindley RG, Mostafid AH, Brierly RD. The 2-year symptomatic and urodynamic results of a prospective randomized trial of interstitial radiofrequency therapy vs transurethral resection of the prostate. BJU Int 2001;88:217-220. [PubMed: 11488732]

5. Geurts JW, van Wijk RM, Wynne HJ. Radiofrequency lesioning of dorsal root ganglia for chronic lumbosacral radicular pain: a randomised, double-blind, controlled trial. Lancet 2003;361:21-26. [PubMed: 12517462]

6. Bleicher RJ, Allegra DP, Nora DT. Radiofrequency ablation in 447 complex unresectable liver tumors: lessons learned. Ann Surg Oncol 2003;10:52-58. [PubMed: 12513961]

7. Kurokohchi K, Watanabe S, Masaki T. Combined use of percutaneous ethanol injection and radiofrequency ablation for the effective treatment of hepatocellular carcinoma. Int J Oncol 2002;21:841-846. [PubMed: 12239624]

8. Wood TF, Rose DM, Chung M. Radiofrequency ablation of 231 unresectable hepatic tumors: indications, limitations, and complications. Ann Surg Oncol 2000;7:593-600. [PubMed: 11005558]

9. Pavlovich CP, Walther MM, Choyke PL. Percutaneous radio frequency ablation of small renal tumors: initial results. J Urol 2002;167:10-5. [PubMed: 11743264]

10. Gervais DA, McGovern FJ, Arellano RS. Renal cell carcinoma: clinical experience and technical success with radio-frequency ablation of 42 tumors. Radiology 2003;226:417-424. [PubMed: 12563135]

11. Wood BJ, Abraham J, Hvizda JL. Radiofrequency ablation of adrenal tumors and adrenocortical carcinoma metastases. Cancer 2003;97:554-560. [PubMed: 12548596]

12. Pacak K, Fojo T, Goldstein DS. Radiofrequency ablation: a novel approach for treatment of metastatic pheochromocytoma. J Natl Cancer Inst 2001;93:648-649. [PubMed: 11309443]

13. Callstrom MR, Charboneau JW, Goetz MP. Painful metastases involving bone: feasibility of percutaneous CT- and US-guided radio-frequency ablation. Radiology 2002;224:87-97. [PubMed: 12091666]

14. Dupuy DE, Zagoria RJ, Akerley W. Percutaneous radiofrequency ablation of malignancies in the lung. Am J Roentgenol 2000;174:57-59. [PubMed: 10628454]

15. Izzo F, Thomas R, Delrio P. Radiofrequency ablation in patients with primary breast carcinoma: a pilot study in 26 patients. Cancer 2001;92:2036-2044. [PubMed: 11596017]

16. Wood BJ, Fojo A, Levy EB. Radiofrequency ablation of painful neoplasms as palliative therapy: early experience. J Vasc Interv Radiol 2000;11S:207.

17. Goldberg SN, Gazelle GS, Dawson SL. Tissue ablation with radiofrequency using multiprobe arrays. Acad Radiol 1995;2:670-674. [PubMed: 9419623]

18. Lencioni R, Goletti O, Amillotta N. Radio-frequency thermal ablation of liver metastases with a cooled-tip electrode needle: results of a pilot clinical trial. Eur Radiol 1998;8(7):1205-1211.

[PubMed: 9724440] 
19. Miao Y, Ni Y, Yu J. An ex vivo study on radiofrequency tissue ablation: increased lesion size by using an "expandable-wet" electrode. Eur Radiol 2001;11:1841-1847. [PubMed: 11511912]

20. Livraghi T, Goldberg SN, Monti F. Saline-enhanced radio-frequency tissue ablation in the treatment of liver metastases. Radiology 1997;202:205-210. [PubMed: 8988212]

21. de Baere T, Denys A, Wood BJ. Radiofrequency liver ablation: experimental comparative study of water-cooled versus expandable systems. AJR Am J Roentgenol 2001;176:187-192. [PubMed: 11133564]

22. Tait IS, Yong SM, Cuschieri SA. Laparoscopic in situ ablation of liver cancer with cryotherapy and radiofrequency ablation. Br J Surg 2002;89(12):1613-1619. [PubMed: 12445075]

23. Dodd GD 3rd, Frank MS, Aribandi M. Radiofrequency thermal ablation: computer analysis of the size of the thermal injury created by overlapping ablations. AJR Am J Roentgenol 2001;177:777782. [PubMed: 11566672]

24. Goldberg SN, Gazelle GS, Compton CC. Treatment of intrahepatic malignancy with radiofrequency ablation: radiologic-pathologic correlation. Cancer 2000;88:2452-2463. [PubMed: 10861420]

25. Cioni D, Lencioni R, Bartolozzi C. Percutaneous ablation of liver malignancies: imaging evaluation of treatment response. Eur J Ultrasound 2001;13(2):73-93. [PubMed: 11369521]

26. Chopra S, Dodd GD 3rd, Chintapalli KN. Tumor recurrence after radiofrequency thermal ablation of hepatic tumors: spectrum of findings on dual-phase contrast-enhanced CT. AJR Am J Roentgenol 2001;177:381-387. [PubMed: 11461868]

27. Lucey BC, Maher MM, Gervais DA. Bacterial peritonitis: a postulated cause of death associated with hepatic radiofrequency ablation. Clin Radiol 2002;57(8):765-767. [PubMed: 12169291]

28. Di Bisceglie AM. Epidemiology and clinical presentation of hepatocellular carcinoma. J Vasc Interv Radiol 2002;13:S169-S171. [PubMed: 12354833]

29. Okuda K. Natural history of hepatocellular carcinoma including fibrolamellar and hepatocholangiocarcinoma variants. J Gastroenterol Hepatol 2002;17(4):401-405. [PubMed: 11982719]

30. Bowles BJ, Machi J, Limm WM. Safety and efficacy of radio-frequency thermal ablation in advanced liver tumors. Arch Surg 2001;136:864-869. [PubMed: 11485520]

31. Gillams AR, Lees WR. Survival after percutaneous, image-guided, thermal ablation of hepatic metastases from colorectal cancer. Dis Colon Rectum 2000;43:656-661. [PubMed: 10826427]

32. Parikh AA, Curley SA, Fornage BD. Radiofrequency ablation of hepatic metastases. Semin Oncol 2002;29(2):168-182. [PubMed: 11951215]

33. McGahan JP, Dodd GD. Radiofrequency ablation of the liver: current status. Am J Roent 2001;176:316.

34. Topham C, Adam R. Oncosurgery: a new reality in metastatic colorectal carcinoma. Semin Oncol 2002;29(5 Suppl 15):3-10. [PubMed: 12422303]

35. McGahan JP, Browning PD, Brock JM, Tesluk H. Hepatic ablation using radiofrequency electrocautery. Invest Radiol 1990;25:267-270. [PubMed: 2185179]

36. Rossi S, Fornari F, Pathies C, Buscarini L. Thermal lesions induced by $480 \mathrm{kHz}$ localized current field in guinea pig and pig liver. Tumori 1990;76:54-57. [PubMed: 2181746]

37. Rossi S, Stasi MD, Buscarini E, Quaretti P, Garbagnati F, Squassante L, Paties CTS, ilverman DE, Buscarini L. Percutaneous RF interstitial thermal ablation in the treatment of hepatic cancer. AJR 1996;167:759-768. [PubMed: 8751696]

38. Rossi S, Buscarini E, Garbagnati F, Stasi MD, Quaretti P, Rago M, Zangrandi A, Andreola S, Silverman D, Bsucarini L. Percutaneous treatment of small hepatic tumors by an expandable RF needle electrode. AJR 1998;170:1015-1022. [PubMed: 9530052]

39. Buscarini L, Buscarini E, Stasi MD, Vallisa D, Quaretti P, Rocca A. Percutaneous radiofrequency ablation of small hepatocellular carcinoma: long-term results. Eur Radiol 2001;11:914-921. [PubMed: 11419162]

40. Rossi S, Garbagnati F, Rosa L, Azzaretti A, Belloni G, Quaretti P. Radiofrequency thermal ablation for treatment of hepatocellular carcinoma. Int J Clin Oncol 2002;7:225-235. [PubMed: 12202976]

41. Livraghi T, Goldberg SN, Lazzaroni S, Meloni F, Solbiati L, Gazelle GS. Small hepatocellular carcinoma: treatment with radio-frequency ablation versus ethanol injection. Radiology 1999;210:655-661. [PubMed: 10207464] 
42. Solbiati L, Livraghi T, Goldberg SN, Ierace T, Meloni F, Dellanoce M, Cova L, Halpern EF, Gazelle GS. Percutaneous radio-frequency ablation of hepatic metastases from colorectal cancer: long-term results in 117 patients. Radiology 2001;221:159-166. [PubMed: 11568334]

43. D'Ippolito G, Goldberg SN. Radiofrequency ablation of hepatic tumors. Tech Vasc Interv Radiol 2002;5(3):141-155. [PubMed: 12524645]

44. Goldberg SN, Solbiati L. Tumor dissemination after radiofrequency ablation of hepatocellular carcinoma. Hepatology 2001;34:609-611. [PubMed: 11526553]

45. Livraghi T. Tumor dissemination after radiofrequency ablation of hepatocellular carcinoma. Hepatology 2001;34:608-611. [PubMed: 11526552]

46. Livraghi T, Solbiati L, Meloni MF. Treatment of focal liver tumors with percutaneous radio-frequency ablation: complications encountered in a multicenter study. Radiology 2003;226:441-451. [PubMed: 12563138]

47. Dechet CB, Zincke H, Sebo TJ. Prospective analysis of computerized tomography and needle biopsy with permanent sectioning to determine the nature of solid renal masses in adults. J Urol 2003;169:7174. [PubMed: 12478106]

48. Jacomides L, Ogan K, Watumull L. Laparoscopic application of radio frequency energy enables in situ renal tumor ablation and partial nephrectomy. J Urol 2003;169:49-53. [PubMed: 12478100]

49. Gervais DA, Arellano RS, McGovern FJ. The influence of the central tumor component on effectiveness of RF ablation of renal massess: Does central extension preclude successful ablation? Radiol Soc North Am Annual Meeting. 2002

50. Roy-Choudhury SH, Cast JE, Lee-Elliot CE. Percutaneous radiofrequency ablation (RFA) of small renal cell carcinoma (RCC) - medium term outcome. Radiol Soc North Am Annual Meeting. 2002

51. Wood BJ, Grippo J, Pavlovich CP. Percutaneous radio frequency ablation for hematuria. J Urol 2001;166:2303-2304. [PubMed: 11696761]

52. Pinto CH, Taminiau AH, Vanderschueren GM. Technical considerations in CT-guided radiofrequency thermal ablation of osteoid osteoma: tricks of the trade. AJR Am J Roentgenol 2002;179:1633-1642. [PubMed: 12438068]

53. Woertler K, Vestring T, Boettner F. Osteoid osteoma: CT-guided percutaneous radiofrequency ablation and follow-up in 47 patients. J Vasc Interv Radiol 2001;12:717-722. [PubMed: 11389223]

54. Vanderschueren GM, Taminiau AH, Obermann WR. Osteoid osteoma: clinical results with thermocoagulation. Radiology 2002;224:82-86. [PubMed: 12091665]

55. Callstrom MR, Charboneau JW, Goetz MP. Painful metastases involving bone: feasibility of percutaneous CT- and US-guided radio-frequency ablation. Radiology 2002;224:87-97. [PubMed: 12091666]

56. Callstrom MR, Charboneau JW, Goetz MP. Percutaneous CT/US-guided radiofrequency ablation of painful metastases involving bone: a multicenter international study. Radiol Soc North Am Annual Meeting. 2002

57. Schaefer O, Lohrmann C, Herling M. Combined radiofrequency thermal ablation and percutaneous cementoplasty treatment of a pathologic fracture. J Vasc Interv Radiol 2002;13:1047-1050. [PubMed: 12397128]

58. Wu JS, Wong R, Johnston M. Meta-analysis of dose-fractionation radiotherapy trials for the palliation of painful bone metastases. Int J Radiat Oncol Biol Phys 2003;55:594-605. [PubMed: 12573746] 2003

59. Sewell PE Jr. Percutaneous radiofrequency ablation of primary and secondary pulmonary malignancies using CT guidance. Radiol Soc North Am Annual Meeting. 2002

60. Lee J, Jin G, Lee Y. CT-guided transthoracic radiofrequency ablation for medically inoperable stage I non-small cell lung cancer. Radiol Soc North Am Annual Meeting. 2002

61. Rose SC, Fotoohi M, Levin DL. Cerebral microembolization during radiofrequency ablation of lung malignancies. J Vasc Interv Radiol 2002;13:1051-1054. [PubMed: 12397129]

62. Curley SA, Izzo F. Radiofrequency ablation of primary and metastatic hepatic malignancies. Int $\mathbf{J}$ Clin Oncol 2002;7:72-81. [PubMed: 12018113]

63. Fontana RJ, Hamidullah H, Nghiem H. Percutaneous radiofrequency thermal ablation of hepatocellular carcinoma: a safe and effective bridge to liver transplantation. Liver Transpl Surg 2002;8:1165-1174. 
64. Wiersinga WJ, Jansen MC, Straatsburg IH. Lesion progression with time and the effect of vascular occlusion following radiofrequency ablation of the liver. Br J Surg 2003;90:306-312. [PubMed: 12594665]

65. Yamasaki T, Kurokawa F, Shirahashi H. Percutaneous radiofrequency ablation therapy for patients with hepatocellular carcinoma during occlusion of hepatic blood flow. Comparison with standard percutaneous radiofrequency ablation therapy. Cancer 2002;95:2353-2360. [PubMed: 12436442]

66. Goldberg SN, Kamel IR, Kruskal JB. Radiofrequency ablation of hepatic tumors: increased tumor destruction with adjuvant liposomal doxorubicin therapy. AJR Am J Roentgenol 2002;179:93-101. [PubMed: 12076912]

67. Anderson GS, Brinkmann F, Soulen MC. FDG positron emission tomography in the surveillance of hepatic tumors treated with radiofrequency ablation. Clin Nucl Med 2003;28:192-197. [PubMed: 12592125]

68. Cioni D, Lencioni R, Rossi S. Radiofrequency thermal ablation of hepatocellular carcinoma: using contrast-enhanced harmonic power doppler sonography to assess treatment outcome. AJR Am J Roentgenol 2001;177:783-788. [PubMed: 11566673]

69. Goldberg SN, Solbiati L, Halpern EF, Gazelle GS. Variables affecting proper system grounding for radiofrequency ablation in an animal model. J Vasc Interv Radiol 2000;11:1069-1075. [PubMed: 10997473]

70. Lu DSK, Raman SS, Vodopich DJ. Effect of vessel size on creation of hepatic radiofrequency lesions in pigs: assessment of the "heat-sink" effect. Am J Roentgenol 2002;178:47-51. [PubMed: 11756085]

71. Goldberg SN, Ahmed M, Gazelle GS. Radio-frequency thermal ablation with NaCl solution injection: effect of electrical conductivity on tissue heating and coagulation-phantom and porcine liver study. Radiology 2001;219:157-165. [PubMed: 11274551]

72. Kitamoto M, Imagawa M, Yamada H. Radiofrequency ablation in the treatment of small hepatocellular carcinomas: comparison of the radiofrequency effect with and without embolization. Am J Roentgenol 2003;181:997-1003. [PubMed: 14500217] 